\title{
Red Shrimp Are a Rich Source of Nutritionally Vital Lipophilic Compounds: A Comparative Study among Edible Flesh and Processing Waste
}

\author{
Ramesh Kumar Saini ${ }^{1} \mathbb{1}$, Min-Ho Song ${ }^{1}$, Kannan R. R. Rengasamy ${ }^{2,3}$, Eun-Young Ko ${ }^{4}$ and \\ Young-Soo Keum ${ }^{1 \text {,* }}$ \\ 1 Department of Crop Science, Konkuk University, Seoul 143-701, Korea; saini1997@konkuk.ac.kr (R.K.S.); \\ tdasgtaasf@gmail.com (M.-H.S.) \\ 2 Institute of Research and Development, Duy Tan University, Da Nang 550000, Vietnam; \\ rengasamyrrajakannan@duytan.edu.vn \\ 3 Faculty of Environment and Chemical Engineering, Duy Tan University, Da Nang 550000, Vietnam \\ 4 Department of Food Science and Biotechnology of Animal Resources, Konkuk University, Seoul 143-701, \\ Korea; key523@hanmail.net \\ * Correspondence: rational@konkuk.ac.kr
}

Received: 25 July 2020; Accepted: 24 August 2020; Published: 26 August 2020

\begin{abstract}
This study was aimed at comparatively analyzing the sterols, tocopherols and fatty acids from edible flesh and processing waste obtained from three shrimp species, utilizing rapid liquid chromatography (LC)-atmospheric-pressure chemical ionization (APCI)-tandem mass spectrometry (MS/MS) and gas chromatography-mass spectrometry (GC-MS). Results revealed the presence of significantly $(p<0.05)$ high proportions of health-beneficial omega-3 (n3) polyunsaturated fatty acids (PUFAs) in Argentine red shrimp (34.3\% in waste and 38.2\% in the flesh), compared to black tiger shrimp (16.5-24.2\%) and whiteleg shrimp (13.2-22.6\%). Among sterols, cholesterol was found most dominant, accounting in the range 349.4 (white shrimp flesh) to $559.3 \mu \mathrm{g} / \mathrm{g}$ fresh weight (FW) (black shrimp waste). Surprisingly, waste was found to contain a substantially higher amount of $\alpha$-tocopherol, for instance, $21.7 \mu \mathrm{g} / \mathrm{g} \mathrm{FW}$ in edible flesh and $35.3 \mu \mathrm{g} / \mathrm{g}$ FW in the waste of black tiger shrimp. The correlation analysis indicated that shrimp with low total contents of lipids might have higher proportions of health-beneficial long-chain (LC)-n3-PUFAs eicosapentaenoic (EPA) and docosahexaenoic acid (DHA). The fat quality indices, including the high ratios of hypocholesterolemic (h)/hypercholesterolemic (H) fatty acids, and lowest values of the atherogenic index (AI) and thrombogenic index (TI) indicated the health-beneficial potential associated with fat intake from red shrimp. Overall, a significant amount of health-beneficial compounds in edible flesh of studied shrimp confers its extraordinary nutritional benefits. Moreover, considering the richness of processing waste with these compounds, their valorization can be prompted.
\end{abstract}

Keywords: Argentine red shrimp; black tiger shrimp; white leg shrimp; cholesterol; $\alpha$-tocopherol; polyunsaturated fatty acids (PUFAs); shrimp waste valorization

\section{Introduction}

Shrimp are the most economically vital and globally traded commodity among crustaceans and all fish products [1]. According to the FAO statistics, 9.4 million tons of crustaceans (live weight), worth USD 69.3 billion were produced in 2018 [1]. Among them, whiteleg shrimp (Penaeus vannamei) alone accounted for 4.9 million tons of production ( $52.9 \%$ of total crustacean production) [1]. However, the marine capture production is dominated by Argentine red shrimp (Pleoticus muelleri) which accounted for 256 thousand tons of production ( $4 \%$ of the total 6 million tons of marine capture 
production of crustaceans) [1]. Shrimp are a key component of a Mediterranean diet, rich in protein, selenium, vitamin B12, vitamin E, omega-3 (n3) long-chain (LC)-polyunsaturated fatty acids (PUFAs), and astaxanthin, a potent antioxidant carotenoid [2]. Especially, shrimp are a rich source of health-beneficial eicosapentaenoic acid (EPA, n3) and docosahexaenoic acid (DHA, n3) that play the key roles in key regulating body homeostasis [3].

The domestic and industrial processing of shrimp involves the separation of head and carapace residues (waste) and muscles (edible flesh). Studies show that such processing generates $40-60 \%$ of food waste [4]. Given the high contents of nutritionally vital components in shrimp, their processing waste can be utilized to recover these nutrients, which can be utilized as health supplements [5]. Moreover, the valorization of processing this waste can solve the problem of its disposal. Additionally, it can generate surplus revenue which can significantly improve the economics of food production and processing.

Considering that a significant amount of waste is generated from shrimp processing, the present investigation was aimed at analyzing major sterols, tocols (Vit E; a sum of $\alpha-, \beta-, \gamma$-and $\delta$-tocopherol, and $\alpha-, \beta-, \gamma-$, and $\delta$-tocotrienol), and fatty acid from edible flesh and processing waste of three species of shrimp, utilizing modern liquid chromatography (LC)-atmospheric-pressure chemical ionization (APCI)-tandem mass spectrometry (MS/MS). Fatty acids were analyzed by gas chromatography (GC)-mass spectrometry (MS). The fatty acid composition data from edible flesh and processing waste were utilized to determine the fat quality characteristics. The results obtained herein are anticipated to contribute significantly to demonstrate the nutritional significance of shrimp, and valorization potential of shrimp processing waste.

\section{Materials and Methods}

\subsection{Raw Materials, Chemicals, and Solvents}

Three species of shrimp commonly consumed in Korea were procured form the Garak market, Songpa-gu, Seoul in October 2019 (Table 1). Two kg of each species in the frozen stage were brought to the lab, defrosted in lukewarm water, and the head and carapace residues (termed as waste) were manually separated from the edible flesh. The edible flesh and waste were separately homogenized using a food processor, and $10 \mathrm{~g}$ portion was precisely aliquoted to $50 \mathrm{~mL}$ Teflon lined glass tube and stored at $-20^{\circ} \mathrm{C}$ until analysis.

Table 1. List of shrimp samples procured for the study and the amount of waste generated from each species.

\begin{tabular}{cccccc}
\hline S/No. & Common Name & Scientific Name & Place of Origin & DOP * & \% Waste \\
\hline $\mathbf{1}$ & Black tiger shrimp & $\begin{array}{c}\text { Penaeus monodon } \\
\text { Penaeus vannamei syn. }\end{array}$ & $\begin{array}{c}\text { Malaysia } \\
\text { (cultivated) }\end{array}$ & June 2019 & 38.1 \\
$\mathbf{2}$ & Whiteleg shrimp & $\begin{array}{c}\text { Litopenaeus vannamei } \\
\text { Pleoticus muelleri }\end{array}$ & Argentina (natural) & May 2019 & 35.6 \\
$\mathbf{3}$ & Argentine red shrimp & * DoP: Date of packing.
\end{tabular}

Authentic standards of fatty acids methyl esters (FAMEs, 37 mix CRM47885), tocols (mix of $\alpha$-, $\beta$-, $\gamma$-and $\delta$-tocopherol, and $\alpha-, \beta-, \gamma-$, and $\delta$-tocotrienol), and sterols, including $24 \alpha$-ethyl cholesterol, $24 \alpha$-methyl cholesterol, cholesterol, and 5- $\alpha$-cholestan- $3 \beta$-ol (internal standard) were obtained from Merck Ltd., Seoul, South Korea. All organic solvents used for extraction were of high-pressure liquid chromatography (HPLC) grade obtained from Daejung Chemicals \& Metals Co., Ltd., Korea. 


\subsection{Extraction of Major Lipophilic Compounds}

The major lipophilic compounds, including fatty acids, tocols, and sterols, were simultaneously extracted following the previous method [6-8] with minor modification. The details procedure is illustrated in Figure 1. The extracted crude lipids were aliquoted to three fractions, as illustrated in Figure 1 and utilized accordingly. Tocols were analyzed before hydrolysis as suggested by Cruz et al. [6]. Fraction 2 was hydrolyzed following the procedure of Cruz et al. [6] with minor modification (Figure 2A). The extracted crude lipids were converted to fatty acid methyl esters (FAMEs) (Figure 2B) and analyzed by gas chromatograph-mass spectrometry (GC-MS).

\section{Simultaneous extraction of major lipophilic compounds}

$10 \mathrm{~g}$ aliquoted frozen sample in $50 \mathrm{ml}$ Teflon lined glass tube $+40 \mu \mathrm{L}$ of 5 - $\alpha$-cholestan-3 $\beta$-ol (internal standard, $1 \mathrm{mg} / \mathrm{ml}$ in acetone) $+50 \mathrm{mg}$ sodium ascorbate (antioxidant)

Mechanically homogenized with $30 \mathrm{ml}$ isopropanol/hexane (1:1, v/v) containing $0.1 \%$ butylated hydroxytoluene (BHT: w/v; antioxidant)

Bath sonication (JAC-2010; $300 \mathrm{w}, 60 \mathrm{~Hz}$, for $10 \mathrm{~min}$ ) for the efficient disintegration and complete extraction

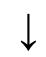

Centrifuged at $8000 \times \mathrm{g}\left(10 \mathrm{~min}\right.$ at $\left.4{ }^{\circ} \mathrm{C}\right)$, supernatant was collected pellets were repeatedly extracted until the pellets became colorless

\section{$\downarrow$}

Supernatants from all extractions were pooled (total volume of 70-100 ml) and partitioned with a double volume of hexane/diethyl ether $(1: 1, \mathrm{v} / \mathrm{v})$ and an equal volume of $1 \mathrm{M}$ sodium chloride $(\mathrm{NaCl})$

The upper diethyl ether phase containing lipophilic compounds was collected and vacuum-dried in a rotary evaporator at $35^{\circ} \mathrm{C}$

\section{$\downarrow$}

Crude lipids congaing fatty acids, tocopherol, and sterols were recovered in $15 \mathrm{ml}$ of methanol/methylene chloride $(2: 1, \mathrm{v} / \mathrm{v})$ containing $0.1 \%$ BHT, and aliquoted as follows:

$\downarrow$

- $1 \mathrm{ml}$ of non-saponified crude lipid sample was syringe filtered and transferred to a HPLC vial for liquid chromatography (LC)-atmospheric-pressure chemical ionization (APCI)- multiple reaction monitoring (MRM) based tandem mass spectrometry (MS/MS) of tocols

口 $3 \mathrm{ml}$ sample was hydrolyzed and utilized to quantify the sterols using LC-MRM-MS/MS

- $2 \mathrm{ml}$ of sample was converted to fatty acid methyl esters (FAMEs) and analysed by gas chromatograph-mass spectrometry (GC-MS)

Figure 1. Method for the simultaneous extraction of major lipophilic compounds. 


\section{(A) Hydrolysis of crude lipid extract for sterols analysis}

$2 \mathrm{ml}$ aliquoted fraction of crude lipids were transferred into a $20 \mathrm{ml}$ glass vial fitted with a Teflonlined screw cap and contents were evaporated to dryness using rotary evaporator at $35^{\circ} \mathrm{C}$

$5 \mathrm{ml}$ of $0.5 \mathrm{M}$ methanolic $\mathrm{KOH}$ were added and placed in a water bath at $80^{\circ} \mathrm{C}$ for $15 \mathrm{~min}$ (for hydrolysis)

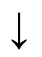

Hydrolyzed samples were immediately cooled in ice, and partitioned with a double volume of hexane/diethyl ether (1:1) and an equal volume of $1 \mathrm{M} \mathrm{NaCl}$

\section{$\downarrow$}

The upper hexane phase containing sterols was carefully collected and vacuum-dried in a rotary evaporator at $35^{\circ} \mathrm{C}$

Sterols were recovered in $2 \mathrm{ml}$ of methanol/methylene chloride (2:1) containing $0.1 \% \mathrm{BHT}$, syringe filtered and transferred to a HPLC vial for LC-MRM-MS/MS analysis

\section{(B) Preparation of fatty acid methyl esters (FAMEs)}

$3 \mathrm{ml}$ aliquoted fraction of crude lipids were transferred into a $20 \mathrm{ml}$ glass vial fitted with a Teflonlined screw cap and contents were evaporated to dryness using rotary evaporator at $35^{\circ} \mathrm{C}$

\section{$\downarrow$}

$3 \mathrm{ml}$ of anhydrous methanolic $\mathrm{HCl}(5 \%, \mathrm{v} / \mathrm{v})$ was added and incubated for $2 \mathrm{~h}$ at $60{ }^{\circ} \mathrm{C}$ in a water bath

After cooling, the FAMEs were sequentially washed with $5 \% \mathrm{NaCl}$ and $2 \%$ sodium bicarbonate $\left(\mathrm{NaHCO}_{3}\right)$ and recovered in $10 \mathrm{ml}$ hexane

A pinch of anhydrous sodium sulfate $\left(\mathrm{Na}_{2} \mathrm{SO}_{4}\right)$ was added to the recovered sample (hexane) to absorb the traces of water

One $\mathrm{ml}$ of sample was filtered through a $0.45 \mu \mathrm{m}$ PTFE syringe filter and transferred to gas chromatography (GC) vial for GC-MS analysis

Figure 2. (A) Method for hydrolysis of crude lipid extract for sterols analysis, and (B) preparation of fatty acid methyl esters (FAMEs).

\subsection{Analysis of Sterols, Tocols, and Fatty Acid Methyl Esters (FAMEs)}

Sterols and tocols were quantified using liquid chromatography (LC)-atmospheric-pressure chemical ionization (APCI)- multiple reaction monitoring (MRM) based tandem mass spectrometry (MS/MS) studies as optimized recently [9]. The optimized instrumental parameters for the simultaneous analysis of sterols and tocols using LC-MRM-MS/MS are illustrated in Table 2. Similarly, the optimized values of collision energy (CE) and declustering potential (DP) of selected Q1 and Q3 MRM transitions for the simultaneous analysis of sterols and tocols using LC-MRM-MS/MS are given in Table 3. 
Table 2. The optimized instrumental parameters for the simultaneous analysis of sterols and tocols using liquid chromatography-multiple reaction monitoring-mass spectrometry (LC-MRM-MS/MS).

\begin{tabular}{|c|c|}
\hline & Instrumentation/Optimized Parameters \\
\hline Mass spectrometer (MS) & $\begin{array}{l}\text { Triple quadrupole MS (API 3200, Applied Biosystems-SCIEX, Framingham, MA, } \\
\text { USA) }\end{array}$ \\
\hline LC system & Exion LC $C^{\mathrm{TM}}$ system (SCIEX, USA) \\
\hline MS operating mode & APCI positive \\
\hline Column & $\mathrm{C}_{30}$ column $(250 \mathrm{~mm} \times 4.6 \mathrm{~mm}, 5 \mu \mathrm{m}$; YMC, Wilmington, $\mathrm{NC}$, USA) \\
\hline Column temperature & $20^{\circ} \mathrm{C}$ \\
\hline Solvent system & $\begin{array}{l}\text { A: Methanol/water }(95 / 5, v / v)+5 \mathrm{mM} \text { ammonium formate }(\mathrm{AF} \text {; dissolved in water; } \\
\text { B: tert-butyl methyl ether/methanol/water }(90 / 7 / 3, v / v / v)+5 \mathrm{mM} \text { AF }\end{array}$ \\
\hline LC gradient elution & $\begin{array}{c}0-100 \% \text { B for a total of } 45 \text { min analysis time, followed by a } 5 \text {-min post-run for the } \\
\text { column equilibrium }\end{array}$ \\
\hline Flow rate & $1 \mathrm{~mL} / \mathrm{min}$ \\
\hline
\end{tabular}

Table 3. The optimized values of collision energy (CE) and declustering potential (DP) of selected Q1 and Q3 MRM transitions for the simultaneous analysis of sterols and tocols using LC-MRM-MS/MS.

\begin{tabular}{|c|c|c|c|c|c|c|c|c|c|}
\hline S/No & $\underset{(m / z)}{\mathrm{Q} 1}$ & $\begin{array}{c}\mathrm{Q} 3 \\
(m / z)\end{array}$ & Component Name & $\mathrm{DP}(\mathrm{V})$ & $\mathrm{EP}(\mathrm{V})$ & $\mathrm{CE}(\mathrm{eV})$ & $\begin{array}{c}\text { CXP } \\
\text { (V) }\end{array}$ & QL/QT & $\begin{array}{c}\text { RT } \\
\text { (min) }\end{array}$ \\
\hline 1 & 430.5 & 165.3 & $\alpha$-tocopherol (1) & 65 & 10 & 40 & 5 & QT & 14.31 \\
\hline 3 & 397.6 & 147.2 & $24 \alpha$-ethyl cholesterol (1) & 60 & 10 & 40 & 5 & QT & 20.06 \\
\hline 4 & 397.6 & 161.4 & $24 \alpha$-ethyl cholesterol (2) & 60 & 10 & 40 & 5 & $\hat{\mathrm{QL}}$ & 20.06 \\
\hline 5 & 383.6 & 161.4 & $24 \alpha$-methyl cholesterol (1) & 70 & 10 & 40 & 5 & $\widehat{Q L}$ & 20.25 \\
\hline 9 & 370.4 & 161.7 & Cholesterol (2) & 70 & 10 & 40 & 5 & $\widehat{Q L}$ & 20.96 \\
\hline 10 & 371.7 & 109.3 & 5- $\alpha$-Cholestan-3- $\beta$-ol (1) & 70 & 10 & 40 & 5 & QT & 21.92 \\
\hline 11 & 371.7 & 135.3 & $5-\alpha-C h o l e s t a n-3-\beta-o l(2)$ & 70 & 10 & 40 & 5 & $\mathrm{QL}$ & 21.92 \\
\hline
\end{tabular}

Fatty acid methyl esters (FAMEs) were analyzed by gas chromatography (GC)-mass spectrometry (MS) utilizing a GC-2010 Plus Gas Chromatograph (Shimadzu, Kyoto, Japan) equipped with a QP2010 SE GC-mass spectrophotometer and an HP-5 column (Agilent; $30 \mathrm{~m}, 0.250 \mu \mathrm{m}$ thick, and $0.25 \mathrm{~mm}$ ID). The injector port and ion source were maintained at 250 and $260^{\circ} \mathrm{C}$, respectively. Helium was used as a carrier gas. The thermal program followed $120-260^{\circ} \mathrm{C}$ in $28 \mathrm{~min}\left(5^{\circ} \mathrm{C} / \mathrm{min}\right.$ linear gradient $)$ and held for $10 \mathrm{~min}$. The FAMEs were precisely identified by comparing their retention time and fragmentation pattern with authentic standards [10].

\subsection{Calculation of Fat Quality Indices}

The fatty acid profile was used to determine several nutritional parameters of lipids, including ratios of PUFAs/saturated fatty acids (SFAs), PUFAs/monounsaturated fatty acids (MUFAs), and hypocholesterolemic $(\mathrm{h}) /$ hypercholesterolemic fatty acids [11,12]. Furthermore, the atherogenic index (AI) [11], and thrombogenic index (TI) [13] were calculated as the following equations:

$$
\begin{gathered}
\mathrm{h} / \mathrm{H}=\frac{\mathrm{C} 18: 1 \mathrm{n} 9 \mathrm{c}+\mathrm{C} 18: 2 \mathrm{n} 6 \mathrm{c}+\mathrm{C} 20: 3 \mathrm{nn}+\mathrm{C} 20: 4 \mathrm{n} 6+\mathrm{C} 20: 5 \mathrm{n} 3+\mathrm{C} 20: 3 \mathrm{n} 3+\mathrm{C} 20: 4 \mathrm{n} 3+\mathrm{C} 22: 4 \mathrm{n} 6+\mathrm{C} 22: 5 \mathrm{n} 6+\mathrm{C} 22: 5 \mathrm{n} 3+\mathrm{C} 22: 6 \mathrm{n} 3}{\mathrm{C} 14: 0+\mathrm{C} 16: 0} \\
\mathrm{AI}=\frac{(4 \times \mathrm{C} 14: 0)+\mathrm{C} 16: 0}{\mathrm{MUFAs}+\mathrm{FUFAs}} \\
\mathrm{TI}=\frac{\mathrm{C} 14: 0+\mathrm{C} 16: 0+\mathrm{C} 18: 0}{(0.5 \times \text { MUFAs })+(0.5 \times \mathrm{n} 6 \text { FUFAs })+(3 \times \mathrm{n} 3 \text { FUFAs })+\left(\frac{\mathrm{n} 3 \text { PUFAs }}{\mathrm{n} 6 \text { PUFAs }}\right)}
\end{gathered}
$$




\subsection{Statistical Analysis and Quality Control}

The samples were extracted in triplicates and analyzed separately. The results were analyzed using IBM SPSS statistics (version 25) employing a one-way analysis of variance (ANOVA), and homogenous subsets were determined (considering a significance level of 0.05 ) to separate the mean values of edible flesh and processing waste of black (black tiger), white (whiteleg), red (Argentine red) shrimp.

\section{Results and Discussion}

\subsection{Fatty Acids Composition and Fat Quality Indices}

In the present study, 31 fatty acids were identified from edible flesh and waste of studied shrimp species (Table 4). In all the samples, palmitic (C16:0) and oleic acid (C18:1n9c) were found in the highest quantity (15.9-20.6\% and 14.6-21.4\%, respectively), followed by DHA (C22:6n3; cis-4,7,10,13,16,19), EPA (C20:5n3; cis-5,8,11,14,17), stearic (C18:0), and arachidonic acid (C20:4n6; cis-5,8,11,14). These six fatty acids together accounted for $57.7 \%$ (white shrimp waste) to $82.3 \%$ (red shrimp edible flesh) of total fatty acids. Among the identified fatty acids, the maximum variation was recorded for linoleic (C18:2n6c; $1.4 \%$ in red shrimp waste and $24.6 \%$ in red shrimp waste), arachidonic, and DHA (Figure 3). The GC-total ion chromatograms (TIC) of black tiger, whiteleg, Argentine red shrimp are were given in Figures A1-A3, respectively (Appendix A). Similarly, the mass spectrums of major identified fatty acids were given in Appendix B. In some samples (e.g., edible flesh of Argentine red shrimp), a fatty acid showed a similar fragmentation pattern, which was tentatively designated as C24:1 isomer (Appendix C).

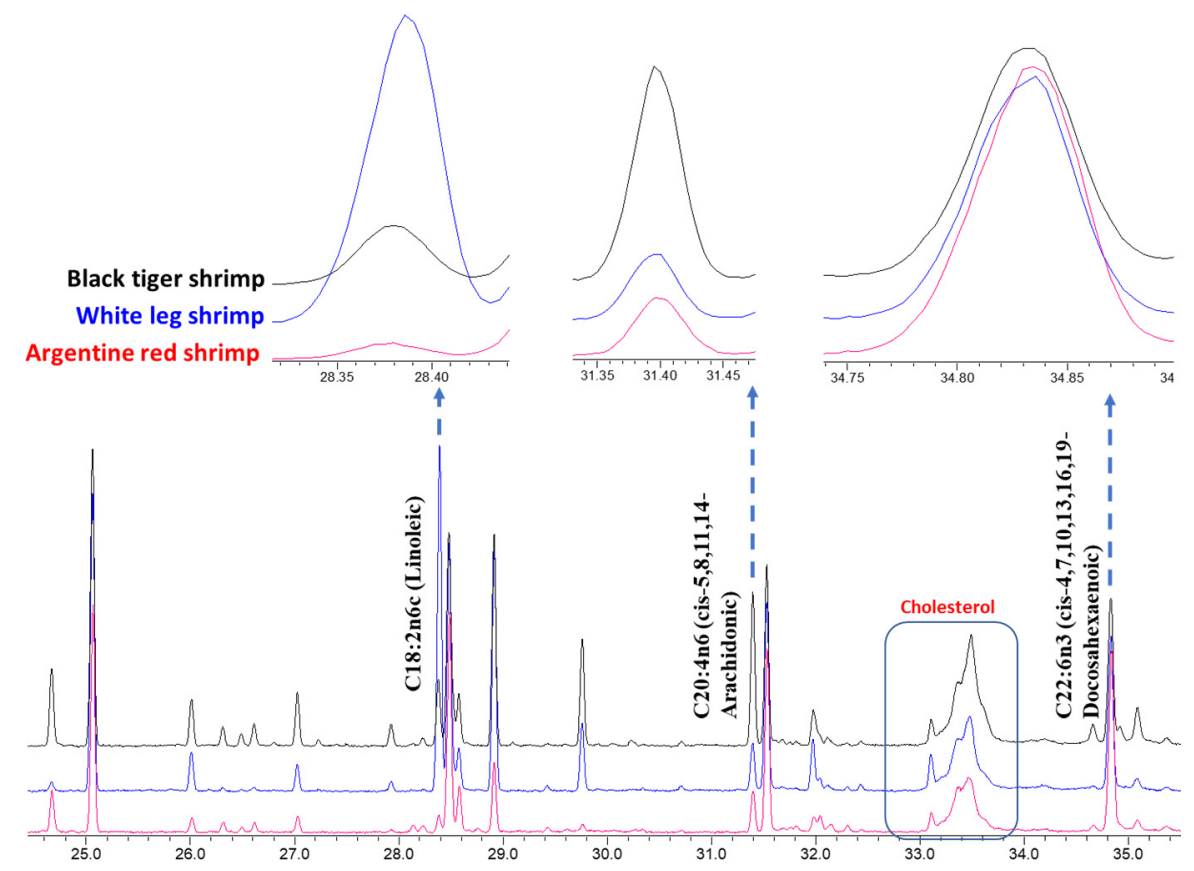

Figure 3. The representative gas chromatography (GC)-total ion chromatogram (TIC) profiles of fatty acid methyl esters (FAMEs) from the edible flesh of three shrimp species. The significant variation in fatty acid composition among black tiger, white leg, and Argentine red shrimp are shown. 
Table 4. The fatty acids composition of waste and edible flesh of three shrimp species

\begin{tabular}{|c|c|c|c|c|c|c|c|c|}
\hline \multirow{2}{*}{ S/No } & \multirow{2}{*}{ RT } & \multirow{2}{*}{ Component (Fatty Acid Methyl Esters) } & \multicolumn{3}{|c|}{ Processing Waste } & \multicolumn{3}{|c|}{ Edible Flesh } \\
\hline & & & Black & White & Red & Black & White & Red \\
\hline 1 & 20.79 & C14:0 (Myristic) & $1.30 \pm 0.01^{\mathrm{a}}$ & $0.48 \pm 0.01$ & $0.62 \pm 0.01$ & $0.59 \pm 0.06^{a}$ & $0.13 \pm 0.04$ & $0.65 \pm 0.09^{a}$ \\
\hline 2 & 22.98 & C15:0 (Pentadecanoic) & $1.20 \pm 0.02^{\mathrm{a}}$ & $0.52 \pm 0.02$ & $0.60 \pm 0.06$ & $0.75 \pm 0.02^{a}$ & $0.39 \pm 0.03$ & $0.60 \pm 0.04$ \\
\hline 3 & 24.58 & C16:1n9c (cis-7; Hexadecenoic acid) & $0.08 \pm 0.05$ & $0.15 \pm 0.01$ & n.d. & n.d. & n.d. & n.d. \\
\hline 4 & 24.67 & C16:1n7c (cis-9; Palmitoleic) & $5.16 \pm 0.19^{a}$ & $1.21 \pm 0.02$ & $3.28 \pm 0.09$ & $4.53 \pm 0.09^{a}$ & $0.48 \pm 0.08$ & $3.47 \pm 0.13$ \\
\hline 5 & 25.07 & C16:0 (Palmitic) & $20.6 \pm 0.71^{a}$ & $15.9 \pm 0.25$ & $16.2 \pm 0.16$ & $16.8 \pm 0.32$ & $16.8 \pm 0.04$ & $18.5 \pm 0.17^{\mathrm{a}}$ \\
\hline 6 & 26.61 & C17:1 (cis-10-Heptadecenoic) & $1.24 \pm 0.05^{\mathrm{a}}$ & $0.25 \pm 0.04$ & $0.76 \pm 0.03$ & $1.25 \pm 0.06^{\mathrm{a}}$ & $0.18 \pm 0.03$ & $0.74 \pm 0.05$ \\
\hline 7 & 27.03 & C17:0 (Heptadecanoic) & $2.93 \pm 0.03^{\mathrm{a}}$ & $0.91 \pm 0.02$ & $1.15 \pm 0.02$ & $2.99 \pm 0.05^{\mathrm{a}}$ & $1.42 \pm 0.02$ & $1.35 \pm 0.15$ \\
\hline 8 & 28.39 & C18:2n6c (Linoleic) & $3.46 \pm 0.01$ & $24.6 \pm 0.21^{\mathrm{a}}$ & $1.49 \pm 0.05$ & $3.79 \pm 0.12$ & $20.1 \pm 0.11^{\mathrm{a}}$ & $1.38 \pm 0.10$ \\
\hline 9 & 28.49 & C18:1n9c (Oleic) & $14.9 \pm 0.24$ & $21.4 \pm 0.33^{\mathrm{a}}$ & $17.8 \pm 0.20$ & $14.6 \pm 0.25$ & $14.9 \pm 0.16$ & $18.7 \pm 0.15^{\mathrm{a}}$ \\
\hline 10 & 28.58 & C18:1n7c (cis-11-octadecenoic) & $3.48 \pm 0.10$ & $3.17 \pm 0.11$ & $4.10 \pm 0.09^{\mathrm{a}}$ & $2.85 \pm 0.22$ & $2.33 \pm 0.14$ & $3.62 \pm 0.08^{\mathrm{a}}$ \\
\hline 11 & 28.92 & $\mathrm{C} 18: 0$ (Stearic) & $10.9 \pm 0.14^{\mathrm{a}}$ & $7.76 \pm 0.04$ & $5.61 \pm 0.12$ & $11.90 \pm 0.32$ & $13.5 \pm 0.15^{\mathrm{a}}$ & $5.66 \pm 0.14$ \\
\hline 12 & 30.71 & C19:0 (Nonadecanoic) & $0.38 \pm 0.00^{\mathrm{a}}$ & $0.29 \pm 0.03$ & $0.21 \pm 0.04$ & $0.26 \pm 0.10^{\mathrm{a}}$ & $0.26 \pm 0.05^{\mathrm{a}}$ & n.d. \\
\hline 13 & 31.40 & C20:4n6 (cis-5,8,11,14-Arachidonic) & $7.20 \pm 0.12^{\mathrm{a}}$ & $1.47 \pm 0.03$ & $4.23 \pm 0.08$ & $8.88 \pm 0.08^{\mathrm{a}}$ & $2.69 \pm 0.13$ & $3.46 \pm 0.03$ \\
\hline 14 & 31.53 & C20:5n3 (cis-5,8,11,14,17-Eicosapentaenoic) & $7.47 \pm 0.03$ & $4.69 \pm 0.03$ & $14.1 \pm 0.06^{\mathrm{a}}$ & $10.1 \pm 0.21$ & $11.1 \pm 0.10$ & $15.8 \pm 0.24^{\mathrm{a}}$ \\
\hline 15 & 31.70 & C20:3n6 (cis-8,11,14-Eicosatrienoic) & $0.42 \pm 0.05$ & $0.22 \pm 0.05$ & $0.41 \pm 0.07$ & $0.33 \pm 0.09^{a}$ & n.d. & $0.20 \pm 0.05^{\mathrm{a}}$ \\
\hline 16 & 31.81 & C20:4n3 (cis 8,11,14,17-eicosatetraenoic; ETA) & $0.24 \pm 0.05$ & $0.28 \pm 0.06$ & $0.53 \pm 0.08^{a}$ & $0.34 \pm 0.24$ & n.d. & $0.28 \pm 0.04$ \\
\hline 17 & 31.98 & C20:2 (cis-11,14-Eicosadienoic) & $5.12 \pm 0.04^{a}$ & $4.42 \pm 0.06$ & $1.89 \pm 0.11$ & $2.98 \pm 0.21^{\mathrm{a}}$ & $2.94 \pm 0.03^{\mathrm{a}}$ & $1.28 \pm 0.11$ \\
\hline 18 & 32.06 & C20:1n9 (cis-11-Eicosenoic) & $0.95 \pm 0.00$ & $1.58 \pm 0.06$ & $2.15 \pm 0.05^{a}$ & n.d. & $0.58 \pm 0.11$ & $1.40 \pm 0.05$ \\
\hline 19 & 32.13 & C20:3n3 (cis-11,14,17-Eicosatrienoic) & $0.40 \pm 0.04$ & $0.82 \pm 0.04$ & $1.08 \pm 0.06^{\mathrm{a}}$ & $0.51 \pm 0.11$ & $0.25 \pm 0.06$ & $0.80 \pm 0.04^{\mathrm{a}}$ \\
\hline 20 & 32.44 & C20:0 (Arachidic) & $0.18 \pm 0.09 \mathrm{P}$ & $0.46 \pm 0.02^{a}$ & $0.31 \pm 0.03$ & $0.21 \pm 0.08^{a}$ & $0.32 \pm 0.06^{\mathrm{a}}$ & n.d. \\
\hline 21 & 34.18 & C21:0 (Henicosanoic) & n.d. & $0.26 \pm 0.07^{a}$ & n.d. & n.d. & n.d. & n.d. \\
\hline 22 & 34.66 & C22:5n6 (cis- 4,7,10,13,16-docosapentaenoic; n6-DPA) & $0.77 \pm 0.08$ & $0.22 \pm 0.02$ & $0.47 \pm 0.08$ & $1.35 \pm 0.10^{\mathrm{a}}$ & n.d. & $0.46 \pm 0.07$ \\
\hline 23 & 34.84 & C22:6n3 (cis-4,7,10,13,16,19-Docosahexaenoic) & $6.15 \pm 0.33$ & $6.48 \pm 0.18$ & $17.2 \pm 0.19^{\mathrm{a}}$ & $10.5 \pm 0.38$ & $10.6 \pm 0.09$ & $20.2 \pm 0.28^{\mathrm{a}}$ \\
\hline 24 & 34.92 & C22:4n6 (cis-7,10,13,16-Docosatetraenoic; DTÁ) & $1.17 \pm 0.03^{a}$ & n.d. & n.d. & $1.00 \pm 0.11^{\mathrm{a}}$ & n.d. & n.d. \\
\hline 25 & 35.09 & C22:5n3 (cis-7,10,13,16,19-docosapentaenoate) & $2.19 \pm 0.28^{a}$ & $0.89 \pm 0.05$ & $1.39 \pm 0.15$ & $2.72 \pm 0.15^{\mathrm{a}}$ & $0.65 \pm 0.03$ & $1.10 \pm 0.29$ \\
\hline 26 & 35.73 & C22:1n9 (Erucic) & $0.00 \pm 0.00$ & $0.21 \pm 0.07$ & $0.83 \pm 0.39^{a}$ & n.d. & n.d. & n.d. \\
\hline 27 & 36.22 & C22:0 (Behenic) & $0.64 \pm 0.08$ & $0.49 \pm 0.04$ & $0.55 \pm 0.11$ & $0.28 \pm 0.02$ & $0.34 \pm 0.01^{\mathrm{a}}$ & n.d. \\
\hline 28 & 38.74 & C23:0 (Tricosanoic) & $0.19 \pm 0.07$ & $0.20 \pm 0.01$ & n.d. & n.d. & n.d. & n.d. \\
\hline 29 & 41.10 & C24:1n9 (Nervonic) & $0.36 \pm 0.10$ & $0.34 \pm 0.08$ & $1.56 \pm 0.08^{\mathrm{a}}$ & n.d. & n.d. & $0.36 \pm 0.13$ \\
\hline 30 & 41.36 & C24:1 isomer & $0.53 \pm 0.11$ & $0.17 \pm 0.02$ & $1.57 \pm 0.12^{\mathrm{a}}$ & $0.22 \pm 0.13^{\mathrm{a}}$ & n.d. & n.d. \\
\hline 31 & 41.86 & C24:0 (Lignoceric) & $0.39 \pm 0.01^{\mathrm{a}}$ & $0.20 \pm 0.04$ & n.d. & $0.20 \pm 0.04^{\mathrm{a}}$ & n.d. & n.d. \\
\hline 32 & & Total SFAs & $38.7 \pm 0.60^{a}$ & $27.4 \pm 0.13$ & $25.2 \pm 0.11$ & $34.0 \pm 0.62^{a}$ & $33.1 \pm 0.06^{\mathrm{a}}$ & $26.7 \pm 0.53$ \\
\hline & & Total MUFAs & $26.7 \pm 0.30$ & $28.5 \pm 0.45$ & $32.0 \pm 0.34^{\mathrm{a}}$ & $23.5 \pm 0.43$ & $18.5 \pm 0.10$ & $28.3 \pm 0.05^{\mathrm{a}}$ \\
\hline \multirow[t]{4}{*}{34} & & Total PUFAs & $34.6 \pm 0.89$ & $44.1 \pm 0.31^{\mathrm{a}}$ & $42.8 \pm 0.44^{a}$ & $42.5 \pm 1.01$ & $48.4 \pm 0.10^{\mathrm{a}}$ & $45.0 \pm 0.49$ \\
\hline & & n3 PUFA & $16.5 \pm 0.71$ & $13.2 \pm 0.17$ & $34.3 \pm 0.26^{a}$ & $24.2 \pm 0.68$ & $22.6 \pm 0.06$ & $38.2 \pm 0.43^{a}$ \\
\hline & & n6 PUFA & $18.1 \pm 0.18$ & $30.9 \pm 0.22^{a}$ & $8.50 \pm 0.24$ & $18.3 \pm 0.41$ & $25.8 \pm 0.14^{\mathrm{a}}$ & $6.77 \pm 0.16$ \\
\hline & & Crude lipids (\% DW) & $5.95 \pm 0.56$ & $7.77 \pm 0.68^{a}$ & $4.61 \pm 0.54$ & $4.60 \pm 0.53$ & $4.50 \pm 0.50$ & $3.65 \pm 0.57$ \\
\hline
\end{tabular}

Values are mean \pm standard deviation of percentages of the total fatty acids, from an average of three determinations. SFAs: total saturated fatty acids; MUFAs: total monounsaturated fatty acids; PUFAs: total polyunsaturated fatty acids; n.d.; not detected; RT: retention time; DW: dry weight. ${ }^{\text {a }}$ The mean value is significantly $(p<0.05)$ highest among the processing waste or edible flesh obtained from black (black tiger), white (white leg), red (Argentine red) shrimp. 
Most crop seeds and vegetable oils, including canola, corn, soybean, and sunflower oils, are rich sources of $\mathrm{n} 6$ fatty acids in the form of linoleic acid with low proportions of $\mathrm{n} 3$ fatty acids, such as $\alpha$-linolenic acid (C18:3n3; ALA) [14]. Meanwhile, health-beneficial LC-n3-PUFAs, such as EPA and DHA, are rare in most seeds commonly utilized for the extraction of vegetable oil [3]. Animals can synthesize n3 LC-PUFAs from common precursor ALA; however, this is with very low efficiency [3]. Thus, direct dietary or supplemental intake of LC-n3-PUFAs is considered beneficial to health [3].

Shrimp are well known to contain a significant amount of EPA, DHA, and other health-beneficial fatty acids [15-17]. The unusual presence of high proportions of linoleic acid and the composition of other fatty acids of white shrimp waste (P. vannamei) observed in the present study agree with previous reports [15,16]. In contrast, Sriket et al. [17] observed only a slight difference for the linoleic acid contents among edible flesh of black tiger shrimp (P. monodon; $13.0 \%$ ) and white shrimp (P. vannamei, $15.6 \%)$. In the present investigation, we observed significantly $(p<0.05)$ low proportions of linoleic acid in black tiger (3.46\% in waste and $3.79 \%$ in edible flesh), compared to whiteleg shrimp $(24.6 \%$ in waste and $20.1 \%$ in edible flesh). Interestingly, in the present study, we observed that linoleic acid is compensated by palmitic, palmitoleic ( $16: 1 \mathrm{n} 7 \mathrm{c}$; cis-9), stearic, and arachidonic acid in the black tiger shrimp. Meanwhile, in the Argentine red shrimp, linoleic acid is compensated by EPA (14.1\% in waste and $15.8 \%$ in edible flesh) and DHA (17.2\% in waste and $20.2 \%$ in edible flesh) (Table 4$)$. Furthermore, with the highest occurrence of EPA and DHA, the highest total amount of n3-PUFAs was recorded in Argentine red shrimp (34.3\% in waste and $38.2 \%$ in edible flesh), with the highest ratio of n3/n6 PUFAs (4.03 in waste and 5.65 in edible flesh) (Table 5). Consumption of PUFAs in such proportions is highly beneficial to reduce the risk of CVD and many other chronic diseases [18]. Furthermore, among the studied shrimp, the lowest amount of total saturated fatty acids (SFAs) were recorded in Argentine red shrimp $(25.2 \%$ in waste and $26.7 \%$ in edible flesh).

Table 5. The fat quality indices of lipids obtained from waste and edible flesh of three shrimp species.

\begin{tabular}{ccccccc}
\hline \multirow{2}{*}{ Indices } & \multicolumn{3}{c}{ Processing Waste } & \multicolumn{3}{c}{ Edible Flesh } \\
\cline { 2 - 7 } & Black & White & Red & Black & White & Red \\
\hline PUFAs/SFAs & $0.89 \pm 0.04$ & $1.61 \pm 0.00$ & $1.70 \pm 0.03^{\mathrm{a}}$ & $1.25 \pm 0.05$ & $1.46 \pm 0.00$ & $1.69 \pm 0.05^{\mathrm{a}}$ \\
PUFAs/MUFAs & $1.30 \pm 0.05$ & $1.55 \pm 0.04^{\mathrm{a}}$ & $1.34 \pm 0.03$ & $1.81 \pm 0.08$ & $2.62 \pm 0.02^{\mathrm{a}}$ & $1.59 \pm 0.01$ \\
n3/n6 & $0.91 \pm 0.03$ & $0.43 \pm 0.01$ & $4.03 \pm 0.10^{\mathrm{a}}$ & $1.32 \pm 0.03$ & $0.88 \pm 0.01$ & $5.65 \pm 0.13^{\mathrm{a}}$ \\
h/H & $2.03 \pm 0.09$ & $3.73 \pm 0.06^{\mathrm{a}}$ & $3.50 \pm 0.04$ & $3.11 \pm 0.08$ & $3.57 \pm 0.02^{\mathrm{a}}$ & $3.27 \pm 0.06$ \\
AI & $0.42 \pm 0.02^{\mathrm{a}}$ & $0.25 \pm 0.00$ & $0.25 \pm 0.00$ & $0.29 \pm 0.01^{\mathrm{a}}$ & $0.26 \pm 0.00$ & $0.29 \pm 0.01^{\mathrm{a}}$ \\
TI & $0.46 \pm 0.02^{\mathrm{a}}$ & $0.35 \pm 0.00$ & $0.18 \pm 0.00$ & $0.31 \pm 0.01$ & $0.33 \pm 0.00^{\mathrm{a}}$ & $0.18 \pm 0.00$ \\
\hline
\end{tabular}

Values are mean \pm standard deviation of percentages of the total fatty acids, from an average of three determinations. SFAs: total saturated fatty acids; MUFAs: total monounsaturated fatty acids; PUFAs: total polyunsaturated fatty acids; h/H: ratios of hypocholesterolemic $(\mathrm{h}) /$ hypercholesterolemic $(\mathrm{H})$ fatty acids; AI: atherogenic index; and TI: thrombogenic index. ${ }^{\text {a }}$ The mean value is significantly $(p<0.05)$ highest among the processing waste or edible flesh obtained from black (black tiger), white (whiteleg), red (Argentine red) shrimp.

Fats with the PUFAs/SFAs ratio of greater than 0.45 are recommended for human consumption to minimize the risk of CVD and other chronic diseases [12]. In the present study, PUFAs/SFAs ratios ranged from 0.89 (black shrimp waste) to 1.70 (red shrimp waste) (Table 5), which falls within the recommendations. Moreover, the fats with lower $\mathrm{AI}$ and $\mathrm{TI}$, and higher ratios of $\mathrm{h} / \mathrm{H}$ fatty acids are recommended for minimizing the risk of CVD [11]. In the present study, the TI varied significantly among the studied shrimp species, and the lowest value of 0.18 was obtained in red shrimp (waste and edible flesh) (Table 5). Surprisingly, Rosa and Nunes [19] also recorded the TI of 0.18 in edible flesh of red shrimp (Aristeus antennatus) and Norway lobster (Nephrops norvegicus). In the present study, the AI ranged from 0.25 (white and red shrimp waste) to 0.42 (black shrimp waste) which is lower than reported from brown shrimp, Crangon crangon (AI of 1.34) [20]. Similarly, in the present investigation, the ratios of $\mathrm{h} / \mathrm{H}$ fatty acids were recorded in the range of 2.03 (black shrimp waste) to 3.73 (white shrimp waste). Furthermore, considering the high ratios of $\mathrm{h} / \mathrm{H}$ fatty acids, shrimp fats are 
health-beneficial, similar to duck meat $(\mathrm{h} / \mathrm{H}=3.5)$, marine fish fillets $(\mathrm{h} / \mathrm{H}=3.1)$, and common carp fillets $(\mathrm{h} / \mathrm{H}=3.4)[12]$.

Marine species, including shrimp, are an excellent source of health-beneficial LC-n3-PUFAs (especially EPA and DHA) [21]. Furthermore, among the studied shrimp species, Argentine red shrimp are the richest source of n3-LC-PUFAs with the lowest amount of SFAs. Moreover, head and carapace residues are found to contain a similar amounts of these health-beneficial fatty acids, which are discarded during the processing.

\subsection{Sterols and Tocols Composition}

In the present study, three major sterols and $\alpha$-tocopherol were identified using rapid LC-APCI-MRM based MS/MS analysis (Figures 4 and 5). The representative LC-MRM-MS/MS chromatograms of sterols and $\alpha$-tocopherol are given in Figure 4. Among waste and edible flesh of studied shrimp, cholesterol was found to be the most dominant, accounting for the range of 349.4 (white leg shrimp flesh) to $559.3 \mu \mathrm{g} / \mathrm{g}$ fresh weight (FW) (black shrimp waste). While other sterols, including $24 \alpha$-ethyl cholesterol ( $\beta$-sitosterol) and $24 \alpha$-methyl cholesterol, were recorded in a small amount (Figure 5).
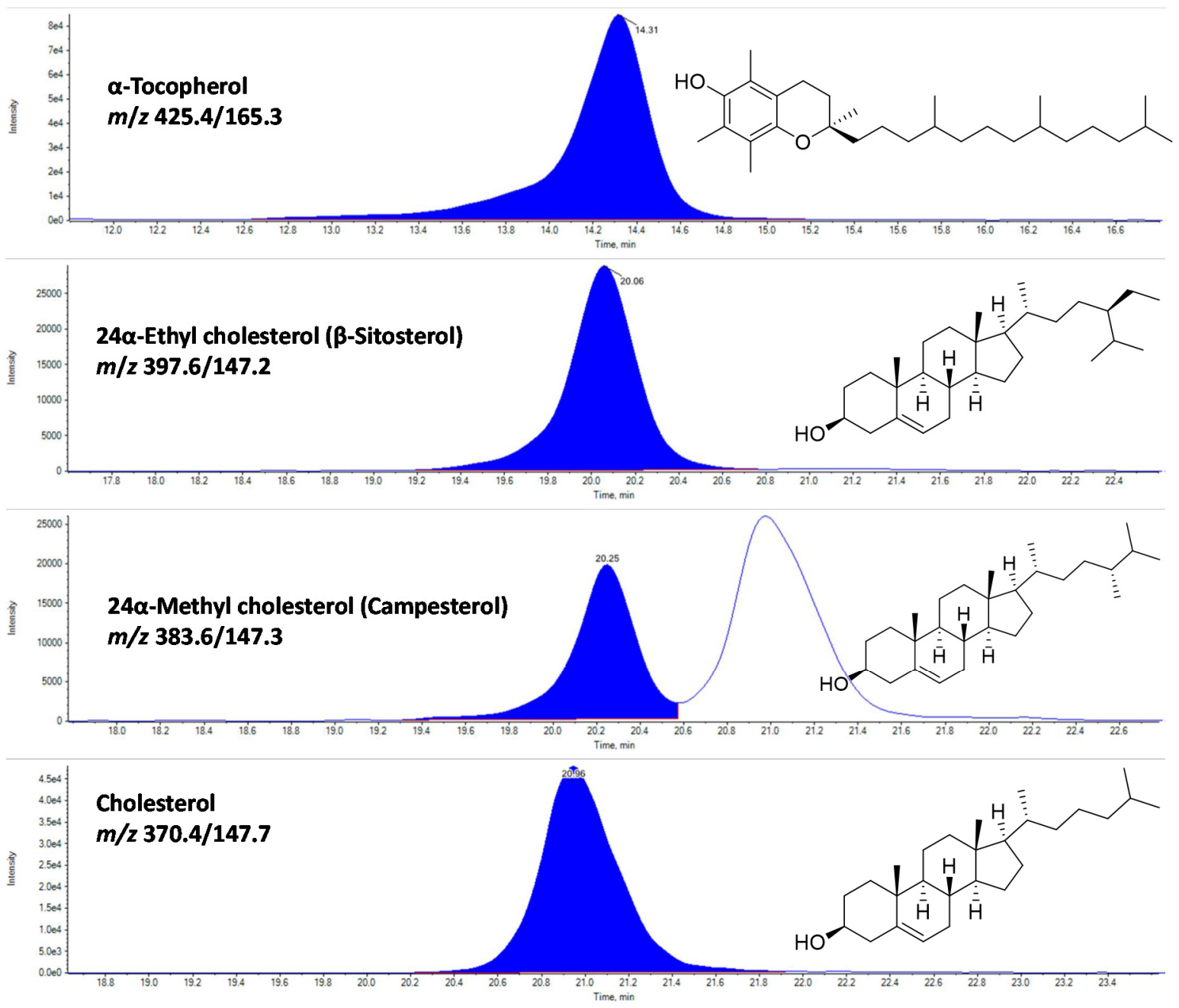

Figure 4. The representative LC-multiple reaction monitoring (MRM)-tandem mass spectrometry (MS/MS) chromatograms of $\alpha$-tocopherol, and sterols in waste and edible flesh of three shrimp species. 

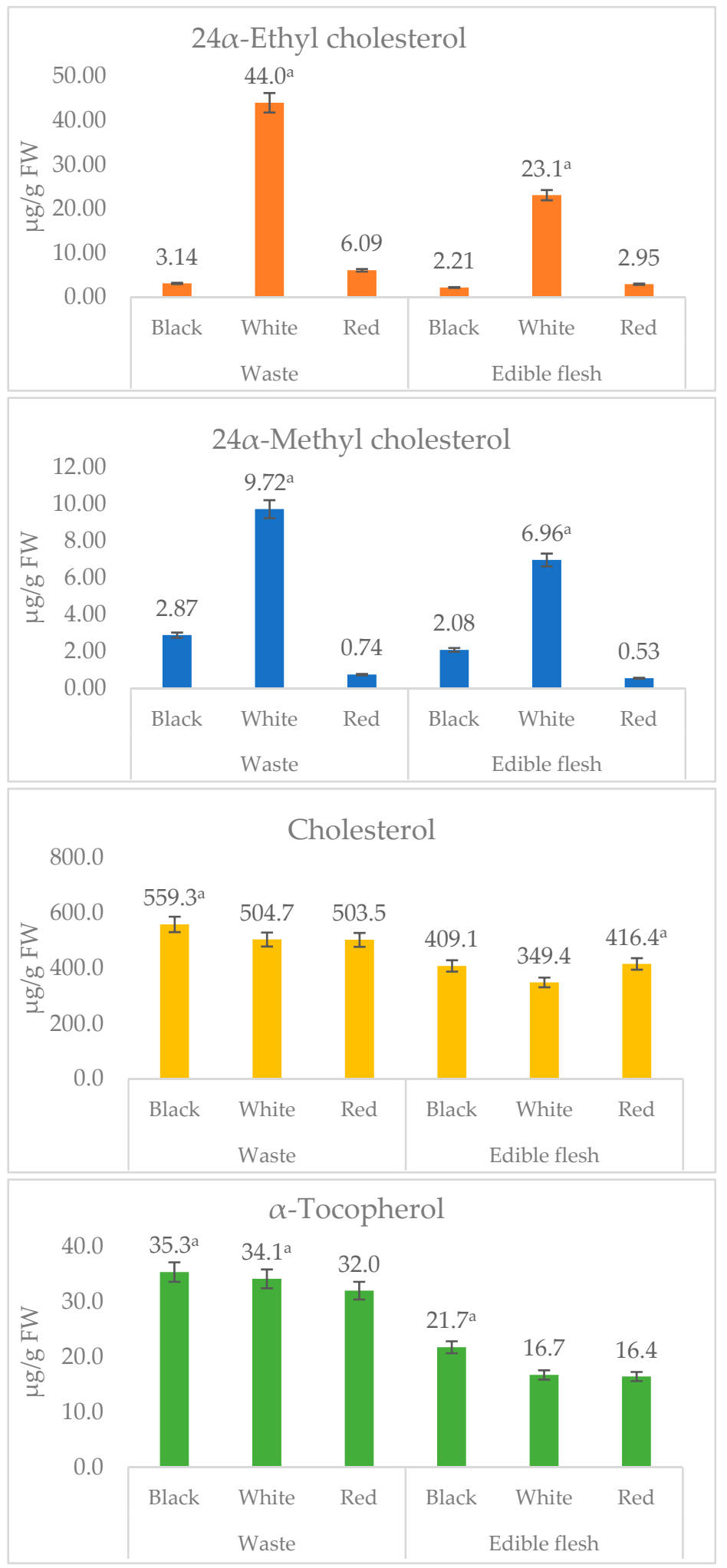

Figure 5. The content of $\alpha$-tocopherol, and sterols in waste and edible flesh of three shrimp species. Values are mean \pm standard deviation of three replicate determinations. ${ }^{a}$ The mean value is significantly $(p<0.05)$ highest among the processing waste or edible flesh obtained from black shrimp (black tiger), white (whiteleg), red (Argentine red) shrimp. 
Similar to the edible flesh of other animals, such as egg, pork, and fish [2,22], shrimp are well known to contain a significant amount of cholesterol [23]. Tsape et al. [23] recorded 1440 and $5210 \mu \mathrm{g} / \mathrm{g}$ FW of cholesterol in muscles and cephalothorax of Penaeus kerathurus, respectively. Turan at al. [20] recorded the $1730 \mu \mathrm{g} / \mathrm{g}$ FW of cholesterol in edible flesh of brown shrimp, C. crangon. In contrast, 608-724 and 578-689 $\mu \mathrm{g} / \mathrm{g}$ FW of cholesterol was recorded in edible flesh of red shrimp (Aristeus antennatus) and pink shrimp (Parapenaeus longirostris), respectively [19]. In contrast, in the present study, we recorded 349.4 (white shrimp flesh) to $559.3 \mu \mathrm{g} / \mathrm{g}$ FW (white shrimp waste) of cholesterol. The results of previous studies and the current study indicate that a significant variation is existing for cholesterol content among shrimp species.

In this study, shrimp waste and edible flesh samples were screened for $\alpha_{-}^{-}, \beta-, \gamma_{-}^{-}$, and $\delta$-tocotrienols and $\alpha-, \beta-, \gamma-$, and $\delta$-tocopherols; however, $\alpha$-tocopherol was only recorded in a significant amount (16.4-35.3 $\mu \mathrm{g} / \mathrm{g}$ FW). Surprisingly, waste was found to contain a significantly higher amount of $\alpha$-tocopherol, for instance, $21.7 \mu \mathrm{g} / \mathrm{g} \mathrm{FW}$ in edible flesh and $35.3 \mu \mathrm{g} / \mathrm{g}$ FW in the waste of black tiger shrimp.

A diet rich in cholesterol is considered a negative nutritional aspect, as excess intake of cholesterol may increase the risk of developing cardiovascular diseases (CVD) [22]. Moreover, cholesterol is known for the initiation of pathophysiological angiogenesis [24]. However, in recent years, several countries have withdrawn the upper limit ( $300 \mathrm{mg} /$ day) of daily cholesterol intake, considering only a slight effect of dietary cholesterol on plasma cholesterol and overall impact on the risk of CVD among the healthy population [22,25]. Moreover, the results of the present study indicate that consumption of $100 \mathrm{~g}$ edible flesh of studied shrimps may provide only $34.9-41.6 \mathrm{mg}$ cholesterol, which is under safe limits. Besides, shrimp are rich in health-beneficial LC-n3-PUFA and $\alpha$-tocopherol, a key cellular antioxidant.

The correlation coefficients ( $r$ ) between major lipophilic compounds (fatty acids, sterols, and $\alpha$-tocopherol) recorded in studied shrimp species are given in Table 6. Correlation analysis shows that EPA and DHA are negatively correlated $(r=-0.920$ and -0.776 , respectively) with crude lipids. The significantly higher proportions of linoleic acid in white leg shrimp lipids correlated positively with $24 \alpha$-ethyl cholesterol $(\mathrm{r}=0.952)$ and $24 \alpha$-methyl cholesterol $(\mathrm{r}=0.983)$, and negatively with EPA $(r=-0.622)$ and DHA $(r=-0.548)$. These observations suggest that shrimp with low total contents of lipids may have higher proportions of EPA and DHA.

\subsection{Valorization Potential of Shrimp Processing Waste}

In the present study, the processing of studied shrimp species generated $38.1 \%$ (black tiger shrimp) to $45.4 \%$ (Argentine red shrimp) waste (Table 1). Furthermore, the observations of an approximately equal amount of LC-n3-PUFAs, and significantly high amount of $\alpha$-tocopherol in waste compared to edible flesh shows that nearly half of the amount of these beneficial nutritional compounds are eliminated during the domestic and industrial processing. Thus, we suggest that these processing waste can be utilized effectively for the recovery of these nutritional vital compounds. Furthermore, shrimp waste contains a significant amount of astaxanthin (e.g., 31-84 $\mu \mathrm{g} / \mathrm{g} \mathrm{FW),} \mathrm{chitin,} \mathrm{and} \mathrm{other} \mathrm{nutritionally}$ and commercially important nutraceuticals [4]. Moreover, $\alpha$-tocopherol is generally supplemented with PUFAs rich lipids to enhance their oxidative stability $[26,27]$. In view of this, the natural presence of a significant amount of $\alpha$-tocopherol in shrimp processing waste is advantageous. Thus, the simultaneous extraction of $\alpha$-tocopherol, LC-n3-PUFA, and other nutraceuticals from shrimp waste can be promoted. The results of previous studies [4] and the present investigation provides support to create a foundation for the effective recovery of nutritional vital compounds from shrimp waste. 
Table 6. Correlation between major lipophilic compounds of studied shrimp species.

\begin{tabular}{|c|c|c|c|c|c|c|c|c|c|c|c|c|c|c|c|}
\hline & C16:1 & C16:0 & C18:2n6c & C18:1n9c & C18:1n9t & C18:0 & C20:4n6 & C20:5n3 & C20:2 & C22:6n3 & $\begin{array}{l}\text { Crude } \\
\text { Lipids }\end{array}$ & $\alpha$-tocopherol & $24 \alpha-\mathrm{EC}$ & $24 \alpha-\mathrm{MC}$ & Cholesterol \\
\hline C16:1 & 1.000 & & & & & & & & & & & & & & \\
\hline C16:0 & 0.640 & 1.000 & & & & & & & & & & & & & \\
\hline C18:2n6c & -0.856 & -0.476 & 1.000 & & & & & & & & & & & & \\
\hline $\mathrm{C} 18 \mathrm{~s} \ln 9 \mathrm{c}$ & -0.393 & -0.407 & 0.356 & 1.000 & & & & & & & & & & & \\
\hline $\mathrm{C} 18: 1 \mathrm{n} 9 \mathrm{t}$ & 0.487 & 0.184 & -0.619 & 0.390 & 1.000 & & & & & & & & & & \\
\hline C18:0 & -0.100 & 0.137 & 0.321 & -0.747 & -0.854 & 1.000 & & & & & & & & & \\
\hline C20:4n6 & 0.845 & 0.438 & -0.650 & -0.720 & 0.020 & 0.373 & 1.000 & & & & & & & & \\
\hline C20:5n3 & 0.141 & 0.000 & -0.622 & -0.135 & 0.342 & -0.391 & 0.005 & 1.000 & & & & & & & \\
\hline $\mathrm{C} 20: 2$ & 0.077 & 0.326 & 0.411 & -0.099 & -0.252 & 0.464 & 0.168 & -0.928 & 1.000 & & & & & & \\
\hline $\mathrm{C} 22: 6 \mathrm{n} 3$ & 0.071 & -0.126 & -0.548 & 0.164 & 0.473 & -0.623 & -0.161 & 0.952 & -0.959 & 1.000 & & & & & \\
\hline Crude Lipids & -0.224 & -0.119 & 0.622 & 0.473 & -0.047 & 0.021 & -0.258 & -0.920 & 0.805 & -0.776 & 1.000 & & & & \\
\hline$\alpha$-tocopherol & 0.245 & 0.110 & 0.047 & 0.279 & 0.489 & -0.236 & 0.057 & -0.603 & 0.653 & -0.511 & 0.750 & 1.000 & & & \\
\hline $24 \alpha-\mathrm{EC}$ & -0.810 & -0.537 & 0.952 & 0.604 & -0.371 & 0.046 & -0.731 & -0.631 & 0.383 & -0.475 & 0.738 & 0.225 & 1.000 & & \\
\hline $24 \alpha-\mathrm{MC}$ & -0.751 & -0.379 & 0.983 & 0.346 & -0.584 & 0.343 & -0.562 & -0.753 & 0.564 & -0.676 & 0.741 & 0.187 & 0.949 & 1.000 & \\
\hline Cholesterol & 0.457 & 0.361 & -0.200 & 0.278 & 0.672 & -0.389 & 0.132 & -0.425 & 0.545 & -0.330 & 0.594 & 0.939 & -0.002 & -0.055 & 1.000 \\
\hline
\end{tabular}

EC: ethyl cholesterol, MC: methyl cholesterol. 


\section{Conclusions}

In summary, key nutritionally valuable lipophilic compounds were quantitatively analyzed in the edible flesh and processing waste utilizing the rapid and sensitive LC-MRM-MS/MS and GC-MS-based approaches. Among the studied shrimp, edible flesh and waste of Argentine red shrimp (P. muelleri) were found rich in health-beneficial LC-n3-PUFA. The fat quality indices, including the high ratios of PUFAs/SFAs and h/H fatty acids, and lowest values of AI and TI, also indicated the health-beneficial potential associated with fat intake from red shrimp. Surprisingly, higher contents of $\alpha$-tocopherol and cholesterol are recorded in processing waste compared to edible flesh. A substantial amount of health-beneficial compounds in the edible flesh of studied shrimp confer its extraordinary nutritional benefits. Moreover, the recovery of these nutritional vital compounds from processing waste can be promoted for food fortification and supplement use.

Author Contributions: Conceptualization, R.K.S. and E.-Y.K.; Methodology, R.K.S.; Validation, E.-Y.K., K.R.R.R. and Y.-S.K.; Formal analysis, R.K.S.; Investigation, R.K.S.; Resources, Y.-S.K.; Writing-original draft preparation, R.K.S.; Writing—review and editing, K.R.R.R.; Supervision, Y.-S.K.; Project administration, M.-H.S.; Funding acquisition, R.K.S. and Y.-S.K. All authors have read and agreed to the published version of the manuscript.

Funding: This paper was supported by the KU research professor program of Konkuk University, Seoul, Korea.

Acknowledgments: This paper was supported by the KU Research Professor Program of Konkuk University, Seoul, Korea. This work was also supported by a grant (2019R1G1A1006815) of the National Research Foundation (NRF) funded by the Ministry of Science and ICT (MSIT), Korea. The APC was funded by an NRF grant (2019R1G1A1006815), MSIT, Korea.

Conflicts of Interest: The authors declare no conflict of interest.

\section{Appendix A}

The representative GC-MS total ion chromatogram (TIC) profiles of fatty acid methyl esters (FAMEs).

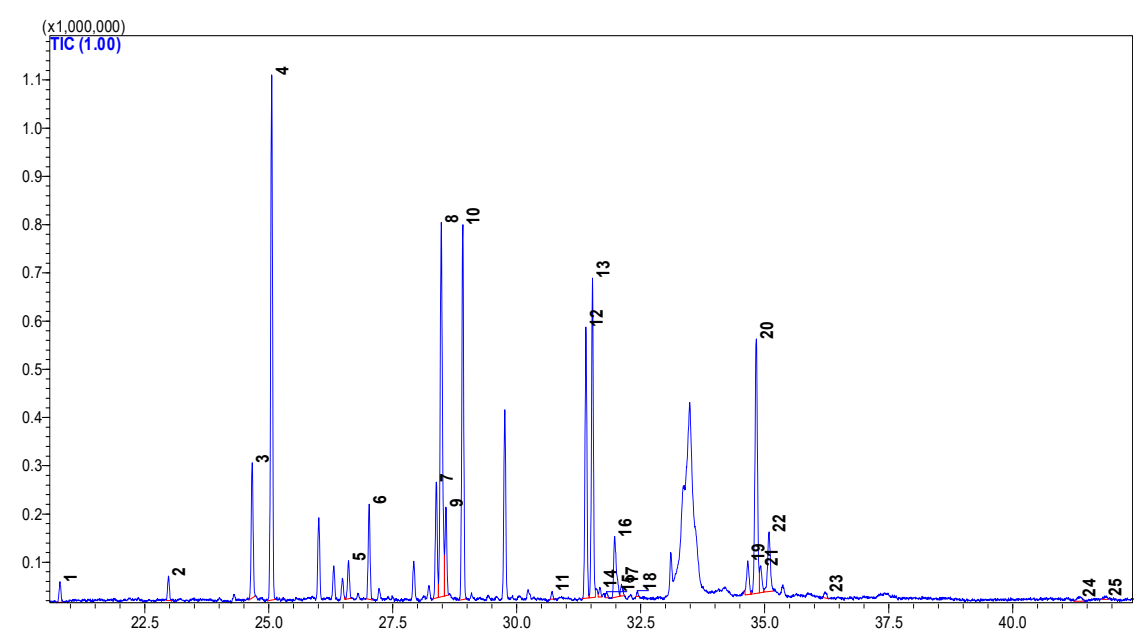

Figure A1. The representative GC-MS total ion chromatogram (TIC) profiles of fatty acid methyl esters (FAMEs) from black tiger shrimp (edible flesh). 1. C14:0 (Myristic), 2. C15:0 (Pentadecanoic), 3. C16:1n7c (cis-9; Palmitoleic), 4. C16:0 (Palmitic), 5. C17:1 (cis-10-Heptadecenoic), 6. C17:0 (Heptadecanoic), 7. C18:2n6c (Linoleic); 8. C18:1n9c (Oleic), 9. C18:1n7c (cis-11-octadecenoic), 10. C18:0 (Stearic), 11. C19:0 (Nonadecanoic), 12. C20:4n6 (cis-5,8,11,14-Arachidonic), 13. C20:5n3 (cis-5,8,11,14,17-Eicosapentaenoic), 14. C20:3n6 (cis-8,11,14-Eicosatrienoic), 15. C20:4n3 (cis 8,11,14,17-eicosatetraenoic; ETA), 16. C20:2 (cis-11,14-Eicosadienoic), 17. C20:3n3 (cis-11,14,17-Eicosatrienoic), 18. C20:0 (Arachidic), 19. C22:5n6 (cis- 4,7,10,13,16-docosapentaenoic; n6-DPA), 20. C22:6n3 (cis-4,7,10,13,16,19-Docosahexaenoic). 21. C22:4n6 (cis-7,10,13,16-Docosatetraenoic; DTA), 22. C22:5n3 (cis-7,10,13,16,19-docosapentaenoate), 23. C22:0 (Behenic), 24. C24:1n9 (Nervonic), and 25. C24:0 (Lignoceric). 


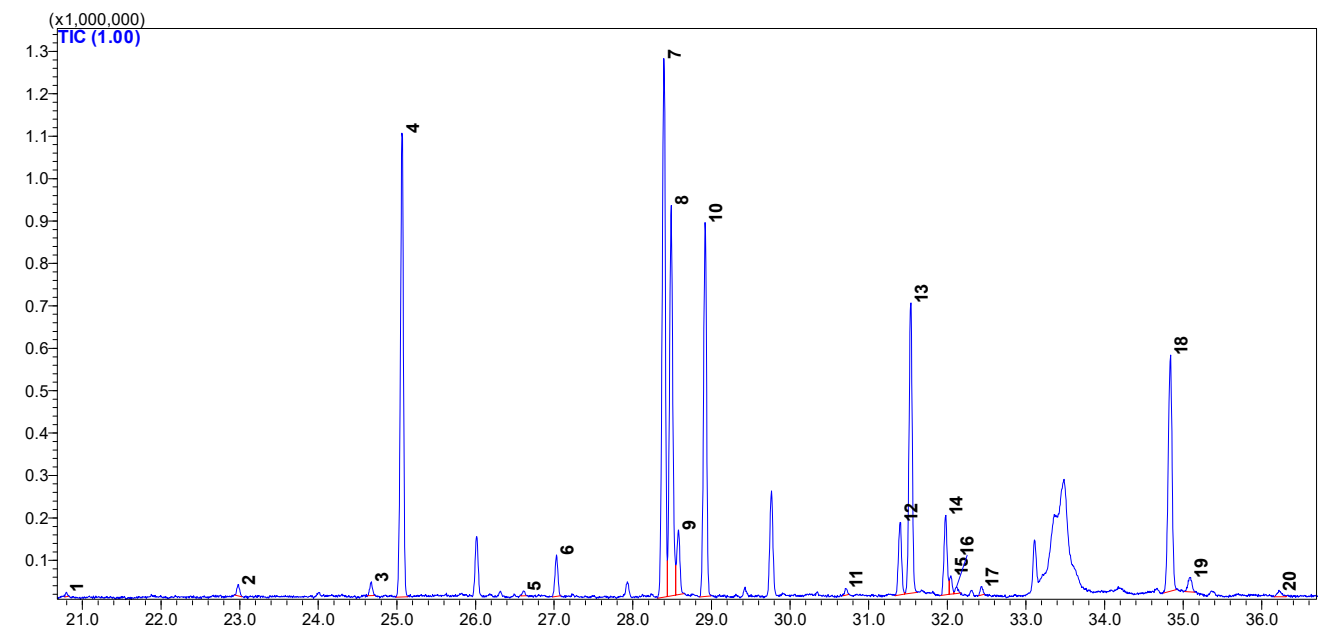

Figure A2. The representative GC-MS total ion chromatogram (TIC) profiles of fatty acid methyl esters (FAME) from whiteleg shrimp (edible flesh). 1. C14:0 (Myristic), 2. C15:0 (Pentadecanoic), 3. C16:1n7c (cis-9; Palmitoleic), 4. C16:0 (Palmitic), 5. C17:1 (cis-10-Heptadecenoic), 6. C17:0 (Heptadecanoic), 7. C18:2n6c (Linoleic), 8. C18:1n9c (Oleic), 9. C18:1n7c (cis-11-octadecenoic), 10. C18:0 (Stearic), 11. C19:0 (Nonadecanoic), 12. C20:4n6 (cis-5,8,11,14-Arachidonic), 13. C20:5n3 (cis-5,8,11,14,17-Eicosapentaenoic), 14. C20:2 (cis-11,14-Eicosadienoic), 15. C20:1n9 (cis-11-Eicosenoic), 16. C20:3n3 (cis-11,14,17-Eicosatrienoic), 17. C20:0 (Arachidic), 18. C22:6n3 (cis-4,7,10,13,16,19-Docosahexaenoic), 19. C22:5n3 (cis-7,10,13,16,19-docosapentaenoate), 20. C22:0 (Behenic).

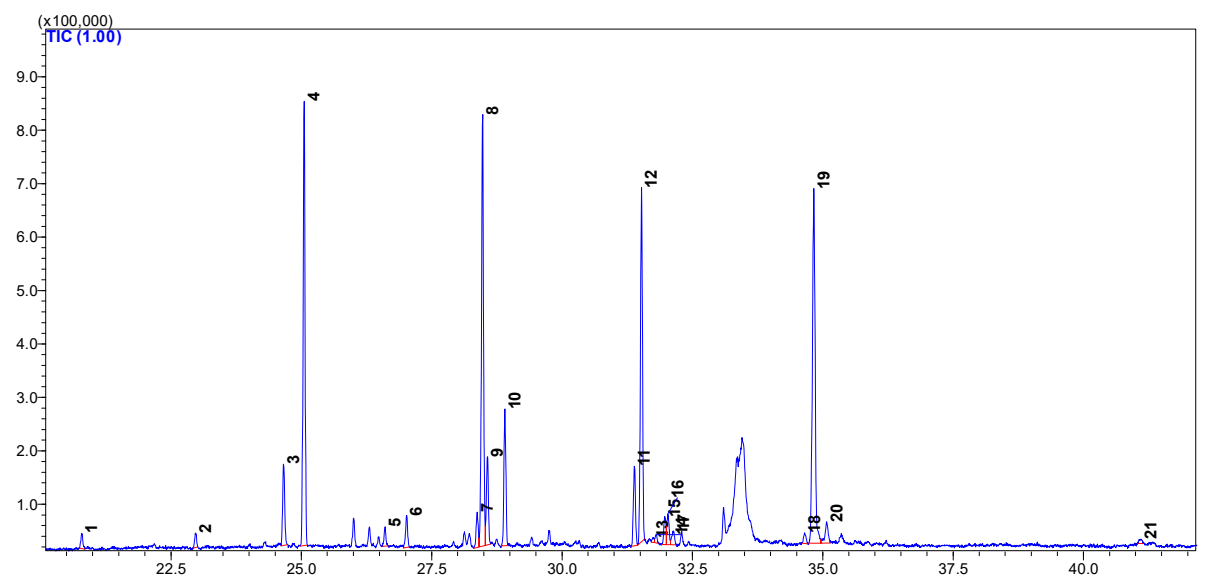

Figure A3. The representative GC-MS total ion chromatogram (TIC) profiles of fatty acid methyl esters (FAME) from Argentine red shrimp (Meat). 1. C14:0 (Myristic), 2. C15:0 (Pentadecanoic), 3. C16:1n7c (cis-9; Palmitoleic), 4. C16:0 (Palmitic), 5. C17:1 (cis-10-Heptadecenoic), 6. C17:0 (Heptadecanoic), 7. C18:2n6c (Linoleic), 8. C18:1n9c (Oleic), 9. C18:1n7c (cis-11-octadecenoic), 10. C18:0 (Stearic), 11. C20:4n6 (cis-5,8,11,14-Arachidonic), 12. C20:5n3 (cis-5,8,11,14,17-Eicosapentaenoic), 13. C20:3n6 (cis-8,11,14-Eicosatrienoic), 14. C20:4n3 (cis 8,11,14,17-eicosatetraenoic; ETA), 15. C20:2 (cis-11,14-Eicosadienoic), 16. C20:1n9 (cis-11-Eicosenoic), 17. C20:3n3 (cis-11,14,17-Eicosatrienoic), 18. C22:5n6 (cis- 4,7,10,13,16-docosapentaenoic; n6-DPA), 19. C22:6n3 (cis-4,7,10,13,16,19-Docosahexaenoic), 20. C22:5n3 (cis-7,10,13,16,19-docosapentaenoate), 21. C24:1n9 (Nervonic). 


\section{Appendix B}

The GC-mass spectrum of major FAME identified in black, white, and red shrimp.
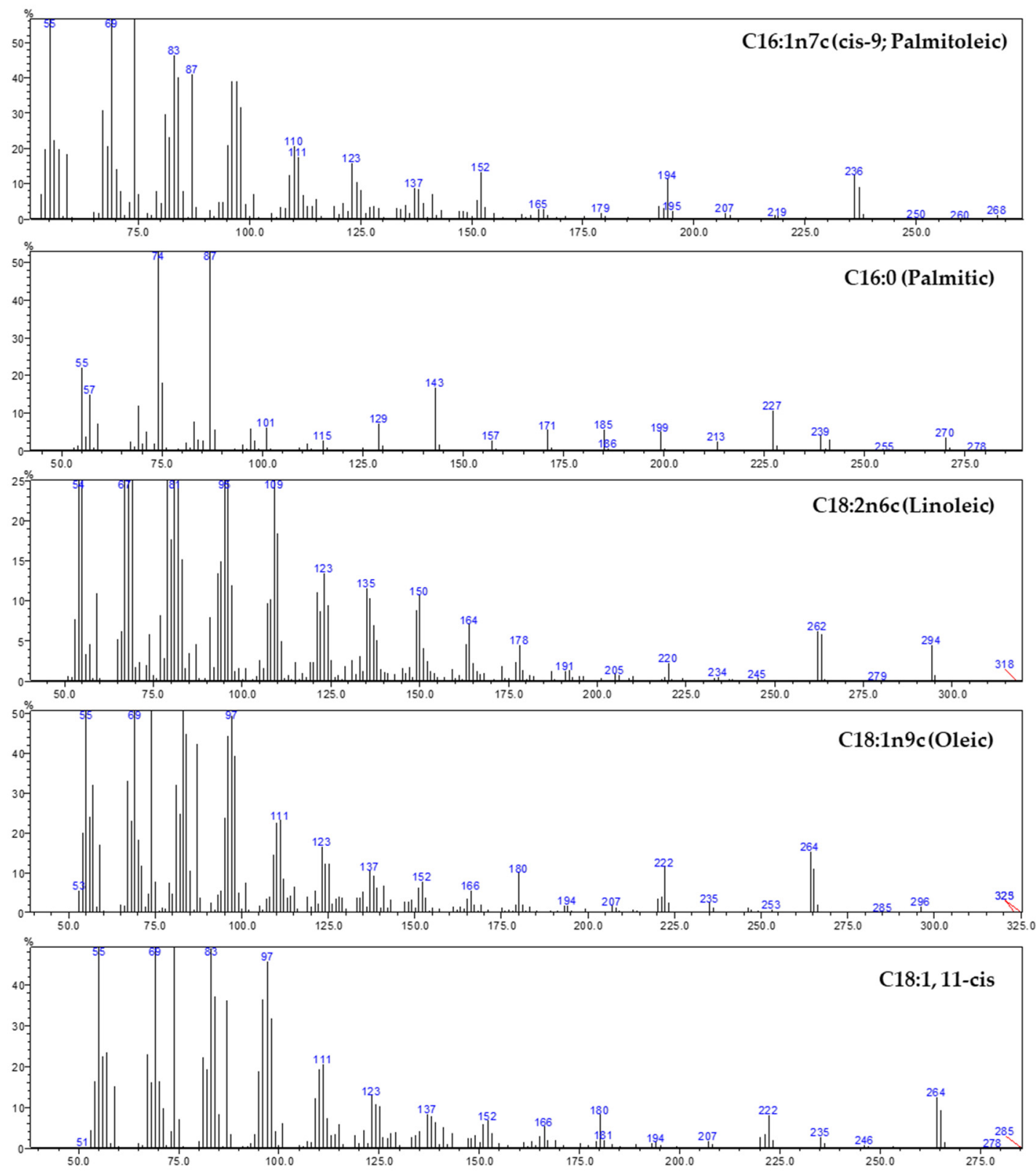

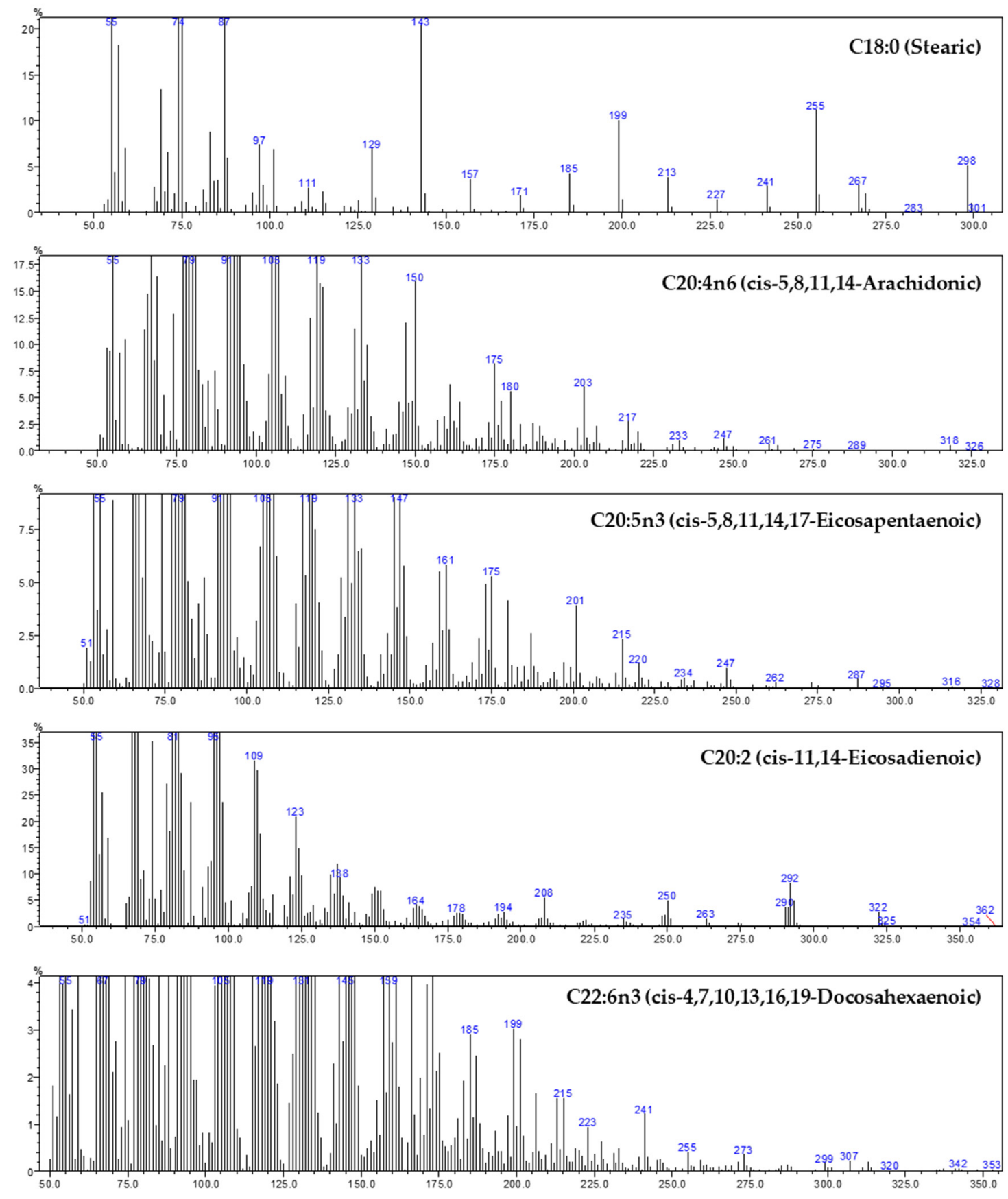


\section{Appendix C}

The tentative identification of peak 25 and 26 as C24:1n9 (Nervonic acid; Argentine red shrimp waste).

\section{Argentinered shrimp waste}
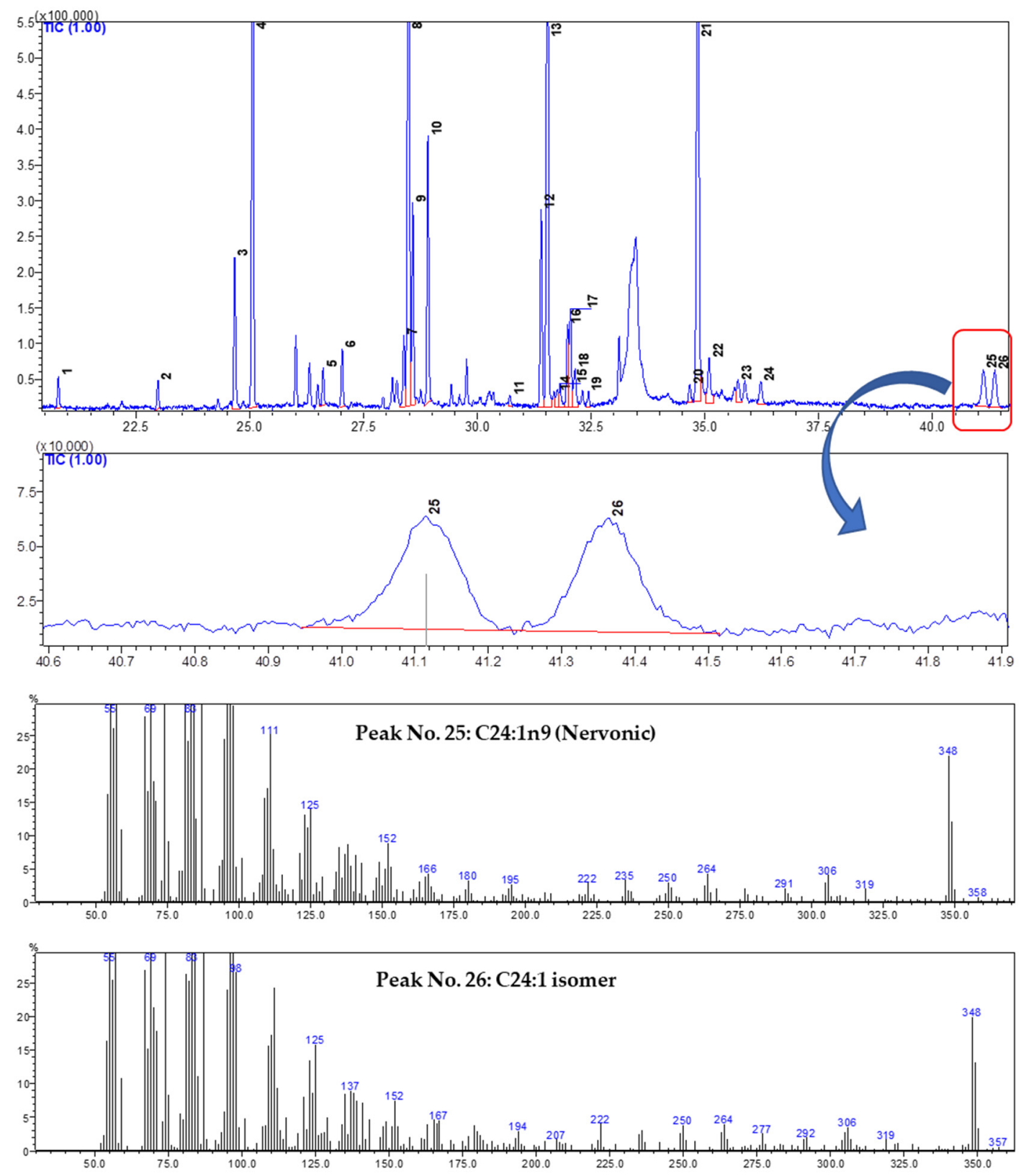

\section{References}

1. FAO. The State of World Fisheries and Aquaculture 2020, Sustainability in Action; FAO: Rome, Italy, 2020; Volume 3.

2. Dayal, J.S.; Ponniah, A.; Khan, H.I.; Babu, E.M.; Ambasankar, K.; Vasagam, K.K. Shrimps-A nutritional perspective. Curr. Sci. 2013, 104, 1487-1491.

3. Saini, R.K.; Keum, Y.S. Omega-3 and omega-6 polyunsaturated fatty acids: Dietary sources, metabolism, and significance-A review. Life Sci. 2018, 203, 255-267. [CrossRef] [PubMed]

4. Saini, R.K.; Moon, S.H.; Keum, Y.S. An updated review on use of tomato pomace and crustacean processing waste to recover commercially vital carotenoids. Food Res. Int. 2018, 108, 516-529. [CrossRef] [PubMed] 
5. Williamson, E.M.; Liu, X.; Izzo, A.A. Trends in use, pharmacology, and clinical applications of emerging herbal nutraceuticals. Br. J. Pharmacol. 2020, 177, 1227-1240. [CrossRef] [PubMed]

6. Cruz, R.; Casal, S.; Mendes, E.; Costa, A.; Santos, C.; Morais, S. Validation of a Single-Extraction Procedure for Sequential Analysis of Vitamin E, Cholesterol, Fatty Acids, and Total Fat in Seafood. Food Anal. Methods 2013, 6, 1196-1204. [CrossRef]

7. Sachindra, N.M.; Bhaskar, N.; Mahendrakar, N.S. Recovery of carotenoids from shrimp waste in organic solvents. Waste Manag. 2006, 26, 1092-1098. [CrossRef]

8. Gulzar, S.; Benjakul, S. Ultrasound Waves Increase the Yield and Carotenoid Content of Lipid Extracted From Cephalothorax of Pacific White Shrimp (Litopenaeus vannamei). Eur. J. Lipid Sci. Technol. 2018, 120, 11. [CrossRef]

9. Saini, R.K.; Keum, Y.-S.; Rengasamy, K.R. Profiling of nutritionally important metabolites in green/red and green perilla (Perilla frutescens Britt.) cultivars: A comparative study. Ind. Crop. Prod. 2020, 151, 112441. [CrossRef]

10. Saini, R.K.; Shetty, N.P.; Giridhar, P. GC-FID/MS Analysis of Fatty Acids in Indian Cultivars of Moringa oleifera: Potential Sources of PUFA. J. Am. Oil Chem. Soc. 2014, 91, 1029-1034. [CrossRef]

11. Ulbricht, T.L.V.; Southgate, D.A.T. Coronary heart disease: Seven dietary factors. Lancet 1991, 338, $985-992$. [CrossRef]

12. Wołoszyn, J.; Haraf, G.; Okruszek, A.; Wereńska, M.; Goluch, Z.; Teleszko, M. Fatty acid profiles and health lipid indices in the breast muscles of local Polish goose varieties. Poult. Sci. 2020, 99, 1216-1224. [CrossRef] [PubMed]

13. Santos-Silva, J.; Bessa, R.J.B.; Santos-Silva, F. Effect of genotype, feeding system and slaughter weight on the quality of light lambs II. Fatty acid composition of meat. Livest. Prod. Sci. 2002, 77, 187-194. [CrossRef]

14. Dorni, C.; Sharma, P.; Saikia, G.; Longvah, T. Fatty acid profile of edible oils and fats consumed in India. Food Chem. 2018, 238, 9-15. [CrossRef] [PubMed]

15. Gómez-Estaca, J.; Calvo, M.M.; Álvarez-Acero, I.; Montero, P.; Gómez-Guillén, M.C. Characterization and storage stability of astaxanthin esters, fatty acid profile and $\alpha$-tocopherol of lipid extract from shrimp (L. vannamei) waste with potential applications as food ingredient. Food Chem. 2017, 216, 37-44. [CrossRef]

16. Takeungwongtrakul, S.; Benjakul, S.; H-Kittikun, A. Lipids from cephalothorax and hepatopancreas of Pacific white shrimp (Litopenaeus vannamei): Compositions and deterioration as affected by iced storage. Food Chem. 2012, 134, 2066-2074. [CrossRef]

17. Sriket, P.; Benjakul, S.; Visessanguan, W.; Kijroongrojana, K. Comparative studies on chemical composition and thermal properties of black tiger shrimp (Penaeus monodon) and white shrimp (Penaeus vannamei) meats. Food Chem. 2007, 103, 1199-1207. [CrossRef]

18. Simopoulos, A.P. Evolutionary aspects of the dietary omega-6/omega-3 fatty acid Ratio: Medical implications. In Evolutionary Thinking in Medicine; Springer Nature Switzerland AG: Cham, Switzerland, 2016; pp. 119-134.

19. Rosa, R.; Nunes, M.L. Nutritional quality of red shrimp, Aristeus antennatus (Risso), pink shrimp, Parapenaeus longirostris (Lucas), and Norway lobster, Nephrops norvegicus (Linnaeus). J. Sci. Food Agric. 2004, 84, 89-94. [CrossRef]

20. Turan, H.; Kaya, Y.; Erdem, M.E. Proximate Composition, Cholesterol, and Fatty Acid Content of Brown Shrimp (Crangon crangon L. 1758) from Sinop Region, Black Sea. J. Aquat. Food Prod. Technol. 2011, 20, 100-107. [CrossRef]

21. DURMUŞ, M. Fish oil for human health: Omega-3 fatty acid profiles of marine seafood species. Food Sci. Technol. (Campinas) 2018, 39, 454-461. [CrossRef]

22. Zhu, H.; Chen, Z.-Y. Do We No Longer Need To Worry about Dietary Cholesterol? J. Agric. Food Chem. 2017, 65, 9931-9933. [CrossRef]

23. Tsape, K.; Sinanoglou, V.J.; Miniadis-Meimaroglou, S. Comparative analysis of the fatty acid and sterol profiles of widely consumed Mediterranean crustacean species. Food Chem. 2010, 122, 292-299. [CrossRef]

24. Samson, F.P.; Patrick, A.T.; Fabunmi, T.E.; Yahaya, M.F.; Madu, J.; He, W.; Sripathi, S.R.; Tyndall, J.; Raji, H.; Jee, D.; et al. Oleic Acid, Cholesterol, and Linoleic Acid as Angiogenesis Initiators. ACS Omega 2020. [CrossRef] [PubMed]

25. Kuang, H.; Yang, F.; Zhang, Y.; Wang, T.; Chen, G. The Impact of Egg Nutrient Composition and Its Consumption on Cholesterol Homeostasis. Cholesterol 2018, 2018, 6303810. [CrossRef] [PubMed] 
26. Saini, R.K.; Keum, Y.S. Tocopherols and tocotrienols in plants and their products: A review on methods of extraction, chromatographic separation, and detection. Food Res. Int. 2016, 82, 59-70. [CrossRef]

27. Kamal-Eldin, A.; Budilarto, E. Tocopherols and tocotrienols as antioxidants for food preservation. In Handbook of Antioxidants for Food Preservation; Elsevier Ltd.: Amsterdam, The Netherlands, 2015; pp. 141-159.

(C) 2020 by the authors. Licensee MDPI, Basel, Switzerland. This article is an open access article distributed under the terms and conditions of the Creative Commons Attribution (CC BY) license (http://creativecommons.org/licenses/by/4.0/). 